\title{
Review
}

\section{Selenium and Arsenic-free Sulfide Glasses as Infrared-transmitting Materials for Optical Systems}

\author{
Kohei KADONO* \\ Faculty of Materials Science and Engineering, Kyoto Institute of Technology, Matsugasaki, Sakyo-ku, Kyoto 606-8585, Japan.
}

Received November 20, 2019; Accepted December 25, 2019

\begin{abstract}
In the last few decades, chalcogenide glasses have received considerable attention as infrared-transmitting materials for infrared systems such as surveillance cameras. In this review, two chalcogenide glass groups are introduced, where germanium sulfide and gallium sulfide are used as the main components. Germanium sulfide glass systems comprise Ge-Ga-Sb-S and Ge-Sb-Sn-S systems, whereas gallium sulfide glass systems comprise Ga-Sb-A-S systems $(\mathrm{A}=\mathrm{Sn}, \mathrm{CsX},(\mathrm{X}=\mathrm{Cl}, \mathrm{Br}, \mathrm{I}))$. Although these glass systems are free from selenium and arsenic which are commonly used in chalcogenide glasses, they have wide glass-forming composition regions. The glasses are thermally stable against crystallization and can be shaped by molding. Germanium-free gallium sulfide-based glasses are also transparent up to a wavelength of $\sim 13 \mu \mathrm{m}$, and their optical window almost covers the atmospheric windows. In addition to the glass-forming regions, the fundamental properties of these glasses including the transmission spectra and refractive indices are presented in this review.
\end{abstract}

\section{KEY WORDS}

sulfide glass, chalcogenide glass, infrared-transmitting material, molding, glass-forming region

\section{Introduction}

Surveillance systems or night vision cameras, thermal imaging systems, and sensing systems embedded with infrared optics have received considerable attention from the scientific community owing to the higher demands for safety and security in the society ${ }^{1-5)}$. It is expected that the demand for these infrared systems will not only increase in the conventional and specific area such as aerospace and military applications but also in civil applications with a much larger market. In order to meet the more popular requirements, it is crucial that the infrared systems, and thus, the parts constructing the systems, e.g., optical elements such as lenses and windows, and infrared radiation detectors, should be costeffective and inexpensive.

Germanium crystals have been conventionally used to fabricate the optical elements of infrared systems because of their transparency over a wide infrared spectral range, high refractive index, and low dispersion at infrared wavelengths. Despite their benefits, germanium crystals are costly and difficult to be molded into various shapes such as lenses, which will increase the overall production cost of infrared systems.

Based on social and technical trends, chalcogenide glasses have gained attention as infrared-transmitting materials. Glasses are more attractive than crystals for fabrication of optical elements

* Corresponding author, E-mail: kadono@kit.ac.jp because they can be easily shaped by molding. Owing to the excellent formability of glasses, glasses are suitable for mass production. Thus, the use of glass materials instead of crystals will likely boost the cost-effectiveness of infrared optics.

In this review paper, two sulfide-based glass systems from the chalcogenide glass family are introduced; these glasses systems are free from selenium and arsenic.

\section{Chalcogenide glasses}

For infrared systems such as surveillance systems, thermal imaging systems, and sensing systems, the main questions is, "which wavelengths in the infrared spectrum are applicable for these systems?" If the system is an infrared camera, the system should be capable of detecting infrared radiation travelling through the atmosphere within a wavelength range of $3-5 \mu \mathrm{m}$ and $8-13 \mu \mathrm{m}$. These wavelength ranges are known as atmospheric windows. If the system is used to detect infrared radiation emitted from human bodies, the spectral range of the system is approximated based on the spectrum of black body radiation at $310 \mathrm{~K}$. In this case, the optical elements should be transparent to infrared radiation, with a spectrum peaking at $9.4 \mu \mathrm{m}$ and a tail extended in the long wavelength side. If the system is used to detect organic molecules in the atmosphere or solutions based on the infrared vibrational spectroscopy, the optical elements of the systems should be transparent to infrared radiation within a wavelength range of 
several $\mu \mathrm{m}$ to $10 \mu \mathrm{m}$. This wavelength range is the fingerprint region for organic molecules.

Based on the aforementioned requirements, infrared-transmitting glasses should be transparent to infrared radiation at least up to $13 \mu \mathrm{m}$. There are two types of glass families transparent in this wavelength region: (1) glass systems based on halides (chlorides, bromides, and iodides, except for fluorides) and (2) glass systems based on chalcogen elements. Halide glasses are extremely transparent up to $15-30 \mu \mathrm{m}^{6}$. These glasses have high hygroscopicity and low thermal stability, and therefore, they are not really suitable for practical applications. Hence, chalcogenide glasses appear to be the best candidates for infrared systems.

Chalcogenide glasses emerged as practical materials in place of germanium crystals because they are transparent in the infrared region and they have been used in the optical systems in the last two decades. Chalcogenide glasses are composed of sulfur, selenium, tellurium, and their compounds as the main components. These glasses have excellent optical transmissivity from the visible or near-infrared region up to a wavelength of $10 \mu \mathrm{m}$ and high refractive index (approximately 2 to 3.5 ).

Fig. 1 shows the glass-forming regions of $\mathrm{Ge}-(\mathrm{As}$ or $\mathrm{Sb})-\mathrm{Ch}$ $(\mathrm{Ch}=\mathrm{S}, \mathrm{Se}, \mathrm{Te})$ ternary systems as examples to compare the differences in the glass formability of chalcogenide glasses with different chalcogen elements ${ }^{7}$. In general, selenium-based glass systems have a wider glass-forming region than other chalcogenide glass systems, as well as excellent glass-forming ability and thermal stability. In fact, high-quality germanium selenide-based glasses incorporated with arsenic and antimony selenides have been used in practical applications ${ }^{8)}$. Selenium, arsenic, antimony, and germanium are the elements commonly used to produce chalcogenide glasses with high glass-forming ability and thermal stability $^{7)}$. Tellurium-based glass systems are transparent up to a wavelength of $20 \mu \mathrm{m}$. However, the glass-forming ability for glass systems based on tellurium and its compounds is limited, as shown in Fig. 1. Thus, much effort is still needed to explore the excellent glass-forming systems $\mathrm{s}^{9,10)}$. In contrast, sulfur-based systems have rather wide glass-forming regions, although the regions are slightly smaller than those of the selenium-based glass systems. In general, sulfur-based glass systems have high glassforming ability and thermal stability. In addition, among the sulfurbased systems, selenium and arsenic-free glass systems have been reported. Despite the absence of selenium and arsenic, these glasses have excellent thermal stability against crystallization and good moldability. Therefore, these sulfide-based glass-forming systems are promising infrared-transmitting material candidates for a wide range of civil applications.

\section{Selenium and arsenic-free sulfide glasses for infrared optics}

\subsection{Ge-Ga-Sb-S and Ge-Sb-Sn-S glass systems}

Germanium sulfide (or Ge-S) is a well-known binary glassforming system and is one of the most investigated glass systems. In this review, however, this binary glass system is not described in detail; rather, it suffices to say that the germanium sulfide system consists of two glass-forming composition ranges: (1) S-rich region (10 to 34 at $\%$ of $\mathrm{Ge}$ ) and (2) Ge-rich region (40 to 44 at $\%$ of $\mathrm{Ge})^{11-13)}$. The germanium sulfide ternary system incorporated with antimony also has a wide glass-forming composition range, as shown in Fig. 1. Pseudo-binary $\mathrm{GeS}_{2}-\mathrm{Sb}_{2} \mathrm{~S}_{3}$ glasses can be obtained for almost the entire composition range except for $\mathrm{Sb}_{2} \mathrm{~S}_{3}$ alone, through the conventional melting-cooling method in an evacuated silica glass tube ${ }^{14)}$. It is noted that the color of $\mathrm{GeS}_{2}-\mathrm{Sb}_{2} \mathrm{~S}_{3}$-based glasses drastically varies from transparent light yellow $\left(\mathrm{GeS}_{2}\right.$-rich composition) to dark brown $\left(\mathrm{Sb}_{2} \mathrm{~S}_{3}\right.$-rich composition). For instance, the absorption edge at the short-wavelength side shifts from $484 \mathrm{~nm}(2.56 \mathrm{eV})$ for $80 \mathrm{GeS}_{2} \cdot 20 \mathrm{SbS}_{3 / 2}$ glass to $686 \mathrm{~nm}(1.95 \mathrm{eV})$ for $20 \mathrm{GeS}_{2} \cdot 80 \mathrm{SbS}_{3 / 2}$ glass $^{15)}$.

Furthermore, the Ge-Ga-Sb-S system has a wide range of glassforming compositions. Fig. 2 shows the glass-forming region for the pseudo-ternary $\mathrm{GeS}_{2}-\mathrm{Ga}_{2} \mathrm{~S}_{3}-\mathrm{Sb}_{2} \mathrm{~S}_{3}$ system ${ }^{14)}$. The incorporation of gallium into chalcogenide glass increases the solubility of the rare-earth ions in the glass. Then spectroscopic investigations of rare-earth ions in the gallium-containing glasses have been extensively carried out ${ }^{16,17)}$

Ge-Sb-Sn-S-based glasses are commercially available as infrared-
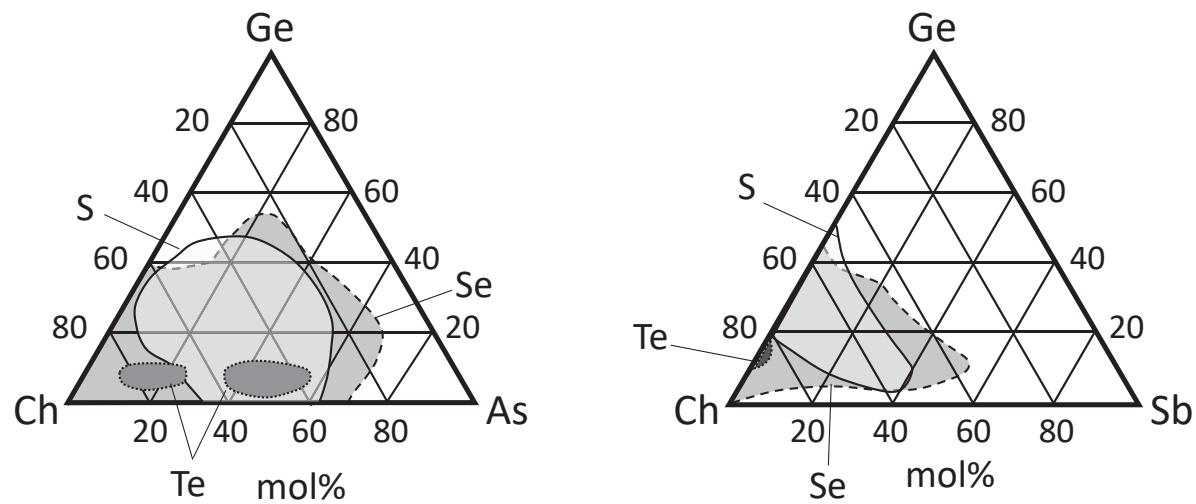

Fig. 1 Glass-forming regions in ternary $\mathrm{Ge}-(\mathrm{As}$ or $\mathrm{Sb})-\mathrm{Ch}(\mathrm{Ch}=\mathrm{S}, \mathrm{Se}, \mathrm{Te})^{7}$. 


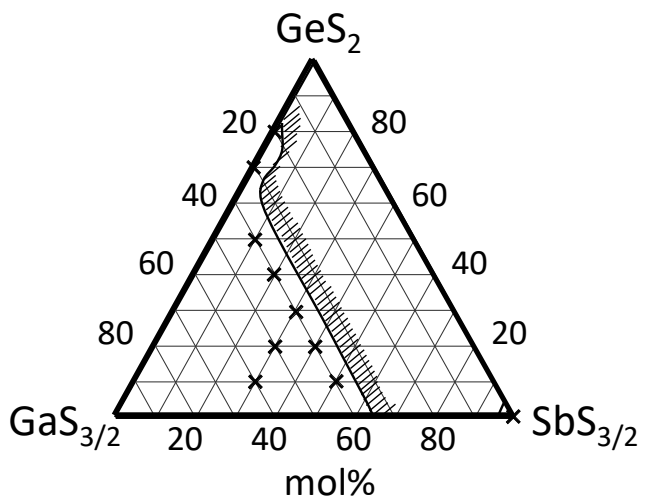

Fig. 2 Glass-forming region in pseudo-ternary $\mathrm{GeS}_{2}-\mathrm{Ga}_{2} \mathrm{~S}_{3}-\mathrm{Sb}_{2} \mathrm{~S}_{3}$ system ${ }^{177}$.

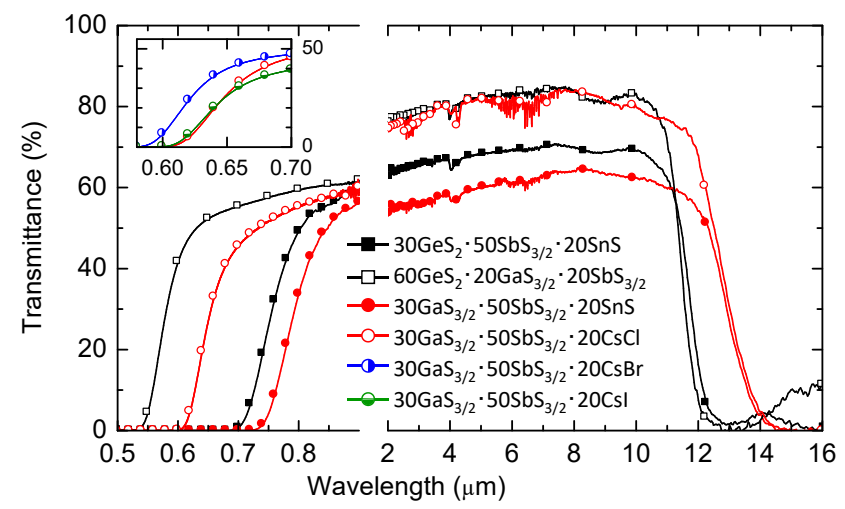

Fig. 3 Transmission spectra of germanium sulfide-based and gallium sulfide -based glasses of various compositions.

transmitting materials ${ }^{18)}$. Fig. 3 shows the typical transmission spectra of the Ge-Sb-Sn-S- and Ge-Ga-Sb-S-based glasses along with those of the gallium sulfide-based glasses as introduced below. It can be seen that the absorption edge at the shortwavelength side varies significantly, depending on the components and compositions of the glasses. The glasses based on the pseudoternary $\mathrm{GeS}_{2}-\mathrm{Ga}_{2} \mathrm{~S}_{3}-\mathrm{Sb}_{2} \mathrm{~S}_{3}$ system are transparent in the visible region and yellow, for high content of Ge. As the Sb content increases, the absorption edge of the glasses shifts towards longer wavelengths and the color of the glasses changes to red, brown, and dark brown while still transmitting visible radiation ${ }^{14,15)}$. However, the incorporation of tin shifts the absorption edge close to the nearinfrared region and makes the glasses opaque in the visible region.
A characteristic feature in the transmission spectra of Ge-Sbased glasses is that the transmission limit in the long wavelength region is located at $11.5 \mu \mathrm{m}$ and the transparent spectral range cannot completely cover the atmospheric window at the long wavelength side. The transmission limit of these Ge-S glasses is determined by the absorption band at $\sim 12.5 \mu \mathrm{m}$ assigned to the stretching vibration of Ge-O impurity.

Table 1 shows the fundamental properties of the Ge-Sb-Sn-Sand Ge-Ga-Sb-S-based glasses. It can be seen that the thermal stability indices, $\Delta T$, of some glasses are more than $200 \mathrm{~K}$, indicating that these glasses are thermally stable and in fact, moldable. The thermal stability index is defined as $\Delta T=T_{\mathrm{c}}-T_{\mathrm{g}}$ where $T_{\mathrm{c}}$ and $T_{\mathrm{g}}$ denote the crystallization and glass transition temperatures, respectively,.

\subsection{Ga-Sb-S system}

Although gallium sulfide $\left(\mathrm{Ga}_{2} \mathrm{~S}_{3}\right)$ is not vitrified though the conventional glass preparation method, i.e., melting-cooling method, glasses based on the binary $\mathrm{Ga}_{2} \mathrm{~S}_{3}-\mathrm{La}_{2} \mathrm{~S}_{3}$ system have been successfully obtained over a relatively wide composition range. This was reported in the 1970s by Loireau-Lozac'h et al. in their pioneering work ${ }^{19)}$. The $\mathrm{Ga}_{2} \mathrm{~S}_{3}-\mathrm{La}_{2} \mathrm{~S}_{3}$-based glasses have received significant attention not as an infrared-transmitting materials; rather, as host glasses for rare-earth ions ${ }^{20,21)}$. The rare-earth ions are incorporated into the glasses by replacing a part of $\mathrm{La}_{2} \mathrm{~S}_{3}$ and these ions act as fluorescent species. These glasses have low phonon energies and thus, it can be expected that these glasses will have high quantum efficiency of emission for the excitation levels even with rather small energy gaps between the excited level and the level just lower it.

Recently, the $\mathrm{Ge}$-free $\mathrm{Ga}-\mathrm{Sb}-\mathrm{S}$ glass systems have been reported as potential candidates for infrared-transmitting materials ${ }^{22-26)}$. The glass-forming region of the ternary Ga-Sb-S system may be relatively small compared with that of the Ge-Sb-S system. In fact, the pseudo-binary $\mathrm{Ga}_{2} \mathrm{~S}_{3}-\mathrm{Sb}_{2} \mathrm{~S}_{3}$ system is vitrified only within the range of $10-30 \mathrm{~mol} \%$ of $x$, where the glass composition is represented by $x \mathrm{GaS}_{3 / 2} \cdot(100-x) \mathrm{SbS}_{3 / 2}{ }^{27,28)}$. By incorporating a third component into the pseudo-binary $\mathrm{Ga}_{2} \mathrm{~S}_{3}-\mathrm{Sb}_{2} \mathrm{~S}_{3}$ system, glasses with a wide compositional region can be obtained, as shown in Fig. 4. The glass-forming regions of the pseudo-ternary $\mathrm{Ga}_{2} \mathrm{~S}_{3}-\mathrm{Sb}_{2} \mathrm{~S}_{3}$ $\mathrm{SnS}$ and $\mathrm{Ga}_{2} \mathrm{~S}_{3}-\mathrm{Sb}_{2} \mathrm{~S}_{3}-\mathrm{CsCl}$ systems are also presented here ${ }^{23)}$. The

Table 1 Glass transition $\left(T_{\mathrm{g}}\right)$ and crystallization $\left(T_{\mathrm{c}}\right)$ temperatures, thermal stability index $(\Delta T)$, density $(d)$, and refractive index $(n)$ at $1544 \mathrm{~nm}$ of glasses in the stoichiometric germanium sulfide-based systems

\begin{tabular}{|c|c|c|c|c|c|c|c|c|}
\hline \multicolumn{4}{|c|}{ Composition (mol\%) } & \multirow{2}{*}{$\begin{array}{c}T_{\mathrm{g}} \\
\left({ }^{\circ} \mathrm{C}\right)\end{array}$} & \multirow{2}{*}{$\begin{array}{c}T_{\mathrm{c}} \\
\left({ }^{\circ} \mathrm{C}\right)\end{array}$} & \multirow{2}{*}{$\begin{array}{l}\Delta T \\
(\mathrm{~K})\end{array}$} & \multirow{2}{*}{$\begin{array}{c}d \\
\left(\mathrm{~g} / \mathrm{cm}^{3}\right)\end{array}$} & \multirow{2}{*}{$\begin{array}{c}n \\
@ 1544 \mathrm{~nm}\end{array}$} \\
\hline $\mathrm{GeS}_{2}$ & $\mathrm{GaS}_{3 / 2}$ & $\mathrm{SbS}_{3 / 2}$ & $\mathrm{SnS}$ & & & & & \\
\hline 30 & - & 70 & - & 263 & - & - & 3.70 & 2.52 \\
\hline 60 & 20 & 20 & - & 363 & 525 & 162 & 3.14 & 2.21 \\
\hline 40 & 20 & 40 & - & 306 & 645 & 339 & 3.40 & 2.36 \\
\hline 20 & 20 & 60 & - & 272 & 408 & 136 & 3.71 & 2.53 \\
\hline 30 & - & 50 & 20 & 251 & 585 & 334 & 3.90 & \\
\hline
\end{tabular}




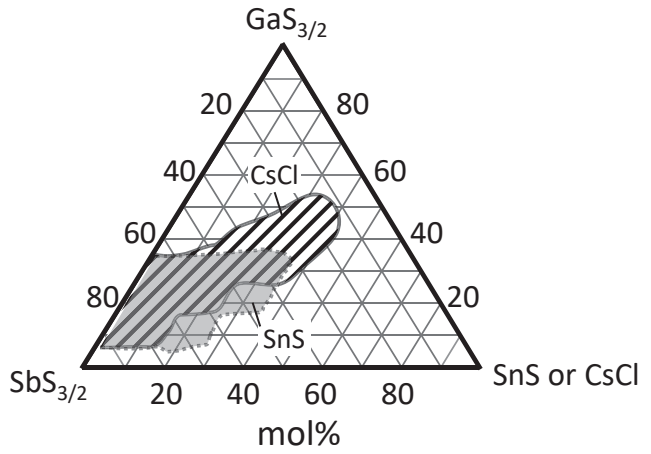

Fig. 4 Glass-forming regions in pseudo-ternary $\mathrm{Ga}_{2} \mathrm{~S}_{3}-\mathrm{Sb}_{2} \mathrm{~S}_{3}-\mathrm{A}(\mathrm{A}=\mathrm{SnS}$ or $\mathrm{CsCl}$ ) systems ${ }^{23)}$.

fundamental properties including the refractive index of the $\mathrm{Ga}_{2} \mathrm{~S}_{3}$ $\mathrm{Sb}_{2} \mathrm{~S}_{3}$-A ( $\mathrm{A}=\mathrm{SnS}$ or $\left.\mathrm{CsCl}\right)$ glasses with different compositions are tabulated in Table 2. It is evident that incorporating a third component increases the thermal stability of the glasses. The $\Delta T$ is higher than $200 \mathrm{~K}$, indicating that these glasses can be shaped by molding. The properties of $\mathrm{Ga}_{2} \mathrm{~S}_{3}-\mathrm{Sb}_{2} \mathrm{~S}_{3}-\mathrm{CsBr}$ and $\mathrm{Ga}_{2} \mathrm{~S}_{3}-\mathrm{Sb}_{2} \mathrm{~S}_{3}$ CsI glasses are also presented in Table 2 and these properties are discussed below.

Fig. 3 shows the transmission spectra of the Ga-Sb-S-based glass incorporated with a third component ${ }^{23)}$. It is noticeable that the transmission limit of the long-wavelength region is located at $13 \mu \mathrm{m}$ and therefore, the transparent spectral window of these glasses can almost cover the atmospheric windows. Because the glasses are germanium-free, the absorption edge that determines the transmission limit of the long-wavelength region is not due to Ge-O stretching, but due to the Ga-O stretching vibration of the oxide impurity at $14.7 \mu \mathrm{m}$. Therefore, the transmission limit of the $\mathrm{Ge}$-free $\mathrm{Ga}-\mathrm{Sb}$-S-based glasses shifts towards longer wavelengths by $1-2 \mu \mathrm{m}$ from those of the Ge-S-based glasses.

Finally, we briefly describe Ga-Sb-S glass systems incorporated with cesium halides such as the $\mathrm{Ga}_{2} \mathrm{~S}_{3}-\mathrm{Sb}_{2} \mathrm{~S}_{3}-\mathrm{CsCl}$ system. Chalcogenide and halide-mixed-anion systems are known as chalcohalide glass systems. This type of glass has already been reported in $1960^{29)}$. Recently, however, these glasses have received considerable attention as a new family of non-oxide glasses. This can be attributed to their variations and the properties of these glasses can be improved by mixing anionic elements of different groups in the periodic table. One of the improved properties is the extended optical window of the glass. Incorporating halides (chlorides, bromides, and iodides) into chalcogenide glasses shifts their absorption edge at the short-wavelength side towards shorter wavelengths without degrading transmission in the longwavelength region. In fact, the absorption edges of the $\mathrm{Ga}_{2} \mathrm{~S}_{3}$ $\mathrm{Sb}_{2} \mathrm{~S}_{3}$ glasses incorporated with $\mathrm{CsX}(\mathrm{X}=\mathrm{Cl}, \mathrm{Br}$, and $\mathrm{I})$ are located at shorter wavelengths compared with those of the $\mathrm{Ga}_{2} \mathrm{~S}_{3}$ $\mathrm{Sb}_{2} \mathrm{~S}_{3}$ glasses without halides ${ }^{30}$. Interestingly, the wavelength shift obtained by incorporating $\mathrm{CsBr}$ is larger than that of $\mathrm{CsCl}$, as shown in the inset of Fig. $3^{30}$. This phenomenon was also observed for other glass systems ${ }^{31}$. However, at present, there is no known reasonable explanation for this.

\section{Concluding remarks}

In this review, two groups of sulfide-based glass systems are introduced: (1) Ge-S-based systems and (2) Ga-S-based systems. Although both systems do not contain selenium and arsenic which are often used as main components in chalcogenide glasses, the glasses are thermally stable against crystallization with good moldability.

In general, the transmission limit of chalcogenide glasses shifts toward longer wavelengths in the following order, sulfides, selenides, and tellurides because of the variations in the phonon energy. The transmission limits are approximately, 10 to $12 \mu \mathrm{m}$, $15 \mu \mathrm{m}$, and up to $20 \mu \mathrm{m}$ for sulfide-, selenide-, and telluridebased glasses, respectively. In many cases, however, the limit for sulfide-based glasses is determined by the absorption edge ascribed to the oxide impurities. For the sulfide-based glasses presented in this review, the transmission limits are determined by the absorption edge assigned to the vibrations of $\mathrm{Ge}-\mathrm{O}$ and $\mathrm{Ga}$ O. Thus, the transmission limit of the germanium sulfide-based glasses is located at $11.5 \mu \mathrm{m}$ and these glasses suffer from the insufficient transmissivity for infrared systems. For the germaniumfree gallium sulfide glasses, however, the transmission limit shifts towards longer wavelengths by $1-1.5 \mu \mathrm{m}$ compared with that of the germanium sulfide-based glasses. Therefore, the transparent spectral range of the gallium sulfide-based glasses almost covers

Table 2 Glass transition $\left(T_{\mathrm{g}}\right)$ and crystallization $\left(T_{\mathrm{c}}\right)$ temperatures, thermal stability index $(\Delta T)$, density $(d)$, and refractive index $(n)$ at $1544 \mathrm{~nm}$ of glasses in the stoichiometric gallium sulfide-based systems

\begin{tabular}{|c|c|c|c|c|c|c|c|c|}
\hline \multicolumn{4}{|c|}{ Composition (mol\%) } & \multirow{2}{*}{$\begin{array}{c}T_{\mathrm{g}} \\
\left({ }^{\circ} \mathrm{C}\right)\end{array}$} & \multirow{2}{*}{$\begin{array}{c}T_{\mathrm{c}} \\
\left({ }^{\circ} \mathrm{C}\right)\end{array}$} & \multirow{2}{*}{$\begin{array}{l}\Delta T \\
(\mathrm{~K})\end{array}$} & \multirow{2}{*}{$\begin{array}{c}d \\
\left(\mathrm{~g} / \mathrm{cm}^{3}\right)\end{array}$} & \multirow{2}{*}{ (a) 1544 nm } \\
\hline $\mathrm{GaS}_{3 / 2}$ & $\mathrm{SbS}_{3 / 2}$ & $\mathrm{SnS}$ & $\operatorname{CsX}$ & & & & & \\
\hline 30 & 70 & - & - & 259 & 358 & 99 & 3.98 & 2.67 \\
\hline 20 & 60 & 20 & - & 245 & 275 & 130 & 4.21 & 2.80 \\
\hline 30 & 50 & 20 & - & 260 & - & $>200$ & 4.13 & 2.74 \\
\hline 30 & 50 & - & $20(\mathrm{Cl})$ & 248 & 462 & 214 & 3.66 & 2.23 \\
\hline 30 & 50 & - & $20(\mathrm{Br})$ & 239 & 451 & 212 & 3.78 & 2.23 \\
\hline 30 & 50 & - & $20(\mathrm{I})$ & 234 & 391 & 157 & 3.89 & 2.29 \\
\hline
\end{tabular}


the atmospheric windows.

In principle, if oxygen impurities are completely eliminated from the sulfide-based glasses, the optical windows of these glasses may significantly expand towards longer wavelengths. For sulfidebased glasses, however, it is difficult to completely eliminate oxide impurities from the raw materials and to prevent the contamination of oxides during the preparation process, which in turn, affects the cost-effectiveness of the glasses. Furthermore, it is crucial to improve the conventional glass preparation method, in which raw materials are melted in an evacuated silica glass tube; the method may become an obstacle to mass production.

\section{References}

1) B. Bureau, X. H. Zhang, F. Smektala, J.-L. Adam, J. Troles, H.-1. Ma, C. Boussard-Plèdel, J. Lucas, P. Lucas, D. L. Coq, M. R. Riley, J. H. Simmons: J. Non-Cryst. Solids, 345\&346 (2004) 276-283.

2) X. H. Zhang, B. Bureau, P. Lucas, C. Boussard-Pledel: J. Lucas, Chem. Eur. J., 14 (2008) 432-442.

3) B. Bureau, C. Boussard-Pledel, P. Lucas, X. Zhang, J. Lucas: Molecules, 14 (2009) 4337-4350.

4) B. Bureau, C. Boussard, S. Cui, R. Chahal, M. L. Anne, V. Nazabal, O. Sire, O. Loréal, P. Lucas, V. S. Cui, R. Chahal, C. Boussard-Plédel, V. Nazabal, J.-L. Doualan, J. Troles, J. Lucas, B. Bureau: Moleclues, 18 (2013) 5373-5388.

5) Monbet, J.-L. Doualan, P. Camy, H. Tariel, F. Charpentier, L. Quetel, J.-L. Adam, J. Lucas: Opt. Eng., 53 (2014) 027101.

6) J. Lucas, J.-L. Adam: in Optical properties of glass, The American Ceramic Society Inc., Westerville, OH (1991) pp. 37-85.

7) M. A. Popescu: Chapter 1 in Non-Crystalline Chalcogenides, Dordrecht, The Netherlands, Kluwer Academic Publishers (2001) pp. 4-102.

8) X. H. Zhang, Y. Guimond, Y. Bellec: J. Non-Cryst. Solids, 326\&327 (2003) 519-523.

9) A. A. Wilhelm, C. Boussard-Plédel, Q. Coulombier, J. Lucas, B. Bureau, P. Lucas: Adv. Mater., 19 (2007) 3796-3800.

10) C. Conseil, J.-C. Bastien, C. Boussard-Plédel, X.-H. Zhang, P. Lucas, S. Dai, J. Lucas, B. Bureau: Opt. Mat. Exp., 2 (2012) 1470-1477.

11) Y. Kawamoto, S. Tsuchihashi: J. Am. Ceram. Soc., 52 (1969) 626-627.
12) Y. Kawamoto, S. Tsuchihashi: J. Am. Ceram. Soc., 54 (1971) 131-135.

13) K. Tanaka, K. Shimakawa: Chapter 1 in Amorphous chalcogenide semiconductors and related materials, Springer (2011) pp. 1-28.

14) M. Ichikawa, T. Wakasugi, K. Kadono: J. Non-Cryst. Solids, 356 (2010) 2235-2240.

15) K. Hosoya, Y. Tokuda, A. Okada, T. Wakasugi, K. Kadono: J. Mater. Res., 34 (2019) 2747-2756.

16) L. B. Shaw, B. Cole, P. A. Thielen, J. S Sanghera, I. D. Aggarwal: IEEE J. Quant. Electron., 48 (2011) 1127-1137.

17) M. Ichikawa, Y. Ishikawa, T. Wakasugi, K. Kadono: J. Mater. Res., 25 (2010) 2111-2119.

18) K. Tani, T. Suetsugu, N. Kaga, M. Tanigawa, T. Morihara, Y. Matsumura, K. Shinohara, T. Einishi, K. Kadono: U.S. Patent 8,603,928 B2 (2013).

19) A.-M. Loireu-Lozac'h, M. Guittard, J. Flahaut: Mat. Res. Bull., 11 (1976) 1489-1496.

20) K. Kadono: J. Cer. Soc. Jpn., 115 (2007) 297-303.

21) H. Higuchi, M. Takahashi, Y. Kawamoto, K. Kadono, T. Ohtsuki, N. Peyghambarian, N. Kitamura: J. Appl. Phys., 83 (1998) 19-27.

22) A. Yang, M. Zhang, L. Lei, Y. Wang, B. Zhang, Z. Yang, D. Tang: J. Am. Ceram. Soc., 99 (2016) 12-15.

23) T. Ashida, T. Wakasugi, A. Okada, K. Kadono: Chem. Lett., 45 (2016) 63-65.

24) J. Qiu, A. Yang, M. Zhang, L. Li, B. Zhang, D. Tang, Z. Yang: J. Am. Ceram. Soc., 100 (2017) 5107-5112.

25) M. Zhang, Z. Yang, H. Zhao, A. Yang, L. Li, H. Tao: J. Alloys Comp., 722 (2017) 166-172.

26) K. Kadono, A. Okada, T. Wakasugi, T. Ashida: US Patent 10,414,687 B2 (2019).

27) S. Barnier, M. Guittard, C. Julien, A. Chilouet: Mat. Res. Bull., 28 (1993) 399-405.

28) A. A. Othman, H. H. Amer, M. A. Osman, A. Dahshan: J. Non-Cryst. Solids, 351 (2005) 130-135.

29) S. S. Flashen, A. D. Pearson, W. R. Northover: J. Appl. Phys., 31 (1960) 219-220.

30) T. Ashida, A. Okada, T. Wakasugi, K. Kadono: J. Cer. Soc. Jpn., 126 (2018) 452-461.

31) K. Kuroda, T. Wakasugi, K. Kadono, Y. Fujimoto: J. Lumin., 181 (2017) 14-18 